ECCOMAS

\section{Proceedia}

COMPDYN 2017

$6^{\text {th }}$ ECCOMAS Thematic Conference on Computational Methods in Structural Dynamics and Earthquake Engineering M. Papadrakakis, M. Fragiadakis (eds.) Rhodes Island, Greece, 15-17 June, 2017

\title{
A NEW NUMERICAL PROCEDURE FOR ASSESSING THE DYNAMIC BEHAVIOUR OF ANCIENT MASONRY TOWERS
}

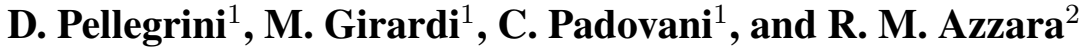 \\ ${ }^{1}$ Institute of Information Science and Technologies "A. Faedo" (ISTI-CNR) \\ Via G. Moruzzi, 1, Pisa, Italy \\ e-mail: \{daniele.pellegrini, maria.girardi, cristina.padovani\}@isti.cnr.it \\ ${ }^{2}$ Istituto Nazionale di Geofisica e Vulcanologia (INGV) - Seismological Observatory of Arezzo \\ Via F. Redi 13a, Arezzo, Italy \\ e-mail: riccardo.azzara@ingv.it
}

Keywords: Structural Health Monitoring, Vibration Response, Masonry Towers, Operational Modal Analysis, Model Updating.

\begin{abstract}
The paper presents a new numerical procedure for the modal analysis of masonry structures implemented in the finite element code NOSA-ITACA, which models masonry as a nonlinear elastic material with zero tensile strength and infinite or bounded compressive strength. The procedure, which allows for taking into account the effects of the stress field and crack distribution within a structure on its natural frequencies and mode shapes, is applied to assess the dynamic behaviour of a medieval bell tower in Lucca. Data recorded by the monitoring system installed on the tower have been processed via suitable modal identification algorithms, which have enabled calculating the tower's modal frequencies, mode shapes and damping ratios. Then, the tower has been analysed via the NOSA-ITACA code and model updating techniques applied to fit the data measured on the tower. The results of the standard modal analysis have been compared to those of modal analyses conducted on the structure subjected to its own weight while taking into account the corresponding crack distribution.
\end{abstract}

(C) 2017 The Authors. Published by Eccomas Proceedia.

Peer-review under responsibility of the organizing committee of COMPDYN 2017.

doi: $10.7712 / 120117.5783 .17652$ 


\section{INTRODUCTION}

Several papers have been devoted to investigating the effects of damage on the vibrations of various structures [1], [2], [3]. With regard to masonry buildings, a common approach consists in simulating the existing damage actually observed on the structure by reducing the stiffness of those elements of the finite element model belonging to the cracked or damaged parts [4], [5], [6], [7]. An analytical approach has been adopted in [8] to formulate an explicit expression linking the fundamental frequency of a masonry-like beam to its maximum transverse displacement. The masonry-like constitutive equation models masonry as a non-linear elastic material with different strengths under tension and compression [9], [10]. This constitutive equation has been implemented in the finite-element code NOSA for the static analysis of masonry bodies [11]. The NOSA code and its updated version NOSA-ITACA 1.0 [12] have been applied to the static and dynamic analysis of many important monuments in Italy.

A new numerical procedure for the modal analysis of masonry structures has been presented in [13] and implemented in the finite element code NOSA-ITACA. In standard modal analysis natural frequencies and mode shapes are calculated by solving the generalized eigenvalue problem involving the mass matrix $M$ and the stiffness matrix $K$, with $K$ determined under the assuption that the structure's constituent materials are linear elastic. The proposed numerical procedure consists of two steps. In the first, the equilibrium problem of the structure subjected to assigned loads is solved, and its numerical solution, consisting of displacements, stress and strain fields, calculated. In the second step, the tangent stiffness matrix, $K^{d}$, is calculated by using the derivative of the stress with respect to the strain [11], obtained in the previous step, and the generalized eigenvalue problem is solved using matrix $K^{d}$ in place of $K$. The procedure allows for taking into account the effects of the stress field and crack distribution within the structure on its natural frequencies and mode shapes.

In this paper the new procedure is briefly recalled and then applied to assess the dynamic behaviour of the medieval "Clock Tower" in Lucca. The ambient vibrations of the tower have been measured by means of four seismometric triaxial stations placed along its height. Data from the monitoring system have been processed via suitable modal identification algorithms [14], which have enabled calculating the tower's modal frequencies, mode shapes and damping ratios [15]. Then, the tower has been analysed via the NOSA-ITACA code, and model updating techniques applied to fit the measured data. The results of the standard modal analysis have been compared to those of modal analysis conducted on the tower subjected to its own weight while taking into account the corresponding crack distribution. The new procedure proposed in the paper has provided more realistic values of the mechanical properties of the tower's constituent materials.

\section{THE NUMERICAL METHOD}

This paper presents a numerical procedure implemented in the NOSA-ITACA code [12], which calculates the natural frequencies and mode shapes of masonry buildings in the presence of cracks [13]. In standard modal analysis the dynamic characteristics of a structure discretized into finite elements are determined by solving the constrained generalized eigenvalue problem

$$
\begin{gathered}
K \phi=\omega^{2} M \phi, \\
T \phi=0,
\end{gathered}
$$

where $K \in \mathbb{R}^{n \times n}$ and $M \in \mathbb{R}^{n \times n}$ are the stiffness and mass matrices, and the integer $n$ is the structure's total number of degrees of freedom. Matrix $K$ is calculated by assuming the 
structure's constituent material to be linear elastic. Condition (2), with $T \in \mathbb{R}^{m \times n}$, and $m \ll n$ expresses the fixed constraints and the master-slave relations assigned to the displacements of the structure. Matrix $M$ is symmetric and positive-definite, $K$ is symmetric and, in view of (2), positive-definite as well [16].

Given the masonry structure under examination, discretized into finite elements, and given the mechanical properties of the structure's constituent masonry-like material, together with the kinematic constraints and loads acting on it, the procedure proposed in [13] consists of the following steps.

Step 0 . A preliminary modal analysis is conducted by assuming the structure's constituent material to be linear elastic. The generalized eigenvalue problem (1)-(2) is then solved, and the natural frequencies $\mathrm{f}_{\mathrm{i}}^{l}=\omega_{\mathrm{i}}^{l} / 2 \pi$ and mode shapes $\phi_{\mathrm{i}}^{l}$ calculated.

Step 1. The nonlinear equilibrium problem of the structure subjected to the assigned loads and boundary conditions is solved through an iterative scheme and its numerical solution, consisting of displacements, strain and stress fields, calculated. The tangent stiffness matrix $K^{d}$ is calculated by using the derivative of the stress with respect to the strain [11].

Step 2. The generalized eigenvalue problem (1)-(2), with matrix $K^{d}$ in place of the elastic stiffness matrix $K$, is solved, and the natural frequencies $f_{i}=\omega_{i} / 2 \pi$ and mode shapes $\phi_{i}$ of the damaged structure calculated.

In order to compare the mode shapes $\phi_{\mathrm{i}}^{l}$ and $\phi_{\mathrm{j}}$, we introduce the quantity

$$
\operatorname{MAC}-M\left(\phi_{\mathrm{i}}^{l}, \phi_{\mathrm{j}}\right)=\frac{\left|\phi_{\mathrm{i}}^{l} \cdot M \phi_{\mathrm{j}}\right|}{\sqrt{\phi_{\mathrm{i}}^{l} \cdot M \phi_{\mathrm{i}}^{l}} \sqrt{\phi_{\mathrm{j}} \cdot M \phi_{\mathrm{j}}}},
$$

which measures the correlation between the $\mathrm{i}-$ th linear elastic mode shape and the $\mathrm{j}-$ th mode shape of the damaged structure. More precisely, if the MAC $-M$ value is close to unity, then the vectors $\phi_{\mathrm{i}}^{l}$ and $\phi_{\mathrm{j}}$ are nearly parallel with respect to the scalar product in $\mathbb{R}^{n}$ induced by matrix $M$.

\section{THE "CLOCK TOWER" IN LUCCA}

The Torre delle Ore ("Clock Tower") in Lucca (Figure 1) dates back to the 13th century. The $48.4 \mathrm{~m}$-high masonry structure has a rectangular cross section of about $5.1 \times 7.1 \mathrm{~m}$ and walls of variable thickness from about $1.77 \mathrm{~m}$ at the base to $0.85 \mathrm{~m}$ at the top. Two barrel vaults are set at heights of about 12.5 and $42.3 \mathrm{~m}$, respectively. At a height of about $33 \mathrm{~m}$ the walls are equipped with 4 steel tie rods of rectangular section $30 \times 30 \mathrm{~mm}$. The bell chamber, made up of four masonry pillars connected by elliptical arches, is separated from the rest of the structure by the upper barrel vault and is covered by a pavilion roof made up of wooden trusses and rafters. The adjacent buildings abut the tower on two sides for a height of about $13 \mathrm{~m}$ and constitute asymmetric boundary conditions. With regard to the materials constituting the masonry tower, no experimental information is available to date. Visual inspection reveals that masonry from the base up to a height of $15 \mathrm{~m}$ is made up of regular stone blocks and thin mortar joints, as are the corners of the walls above this level, as well. The upper walls' central portions are instead made up of regular stone blocks and bricks, also with thin joints. The bell chamber is composed of brick and mortar joints.

In November 2016 the "Clock Tower" was fitted with four high-sensitivity triaxial seismometric stations: they were placed in different configurations (Figure 2) and left active on the 


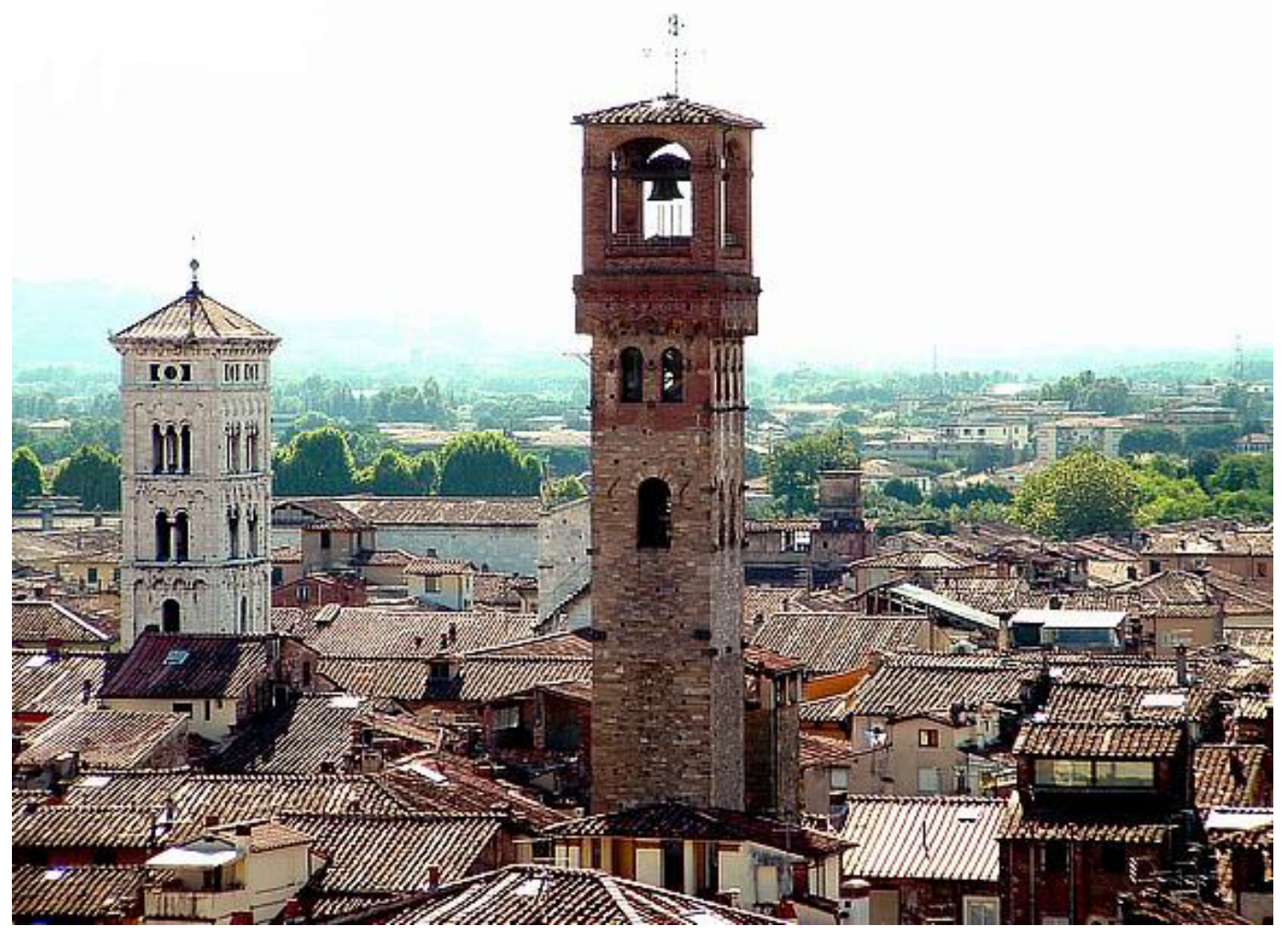

Figure 1: The "Clock Tower" in Lucca.

tower for one day. Data from the instruments, analyzed via OMA techniques [14], allowed us to determine the tower's first four natural frequencies $f_{\mathrm{i}}^{\exp }$ and the corresponding damping ratios and mode shapes [15].

In the following the NOSA-ITACA code is employed, together with model updating techniques, in order to fit the experimental results in the linear elastic and the masonry-like (nonlinear) case. The finite-element model of the tower consists of 11383 brick elements [12]. The four steel tie rods fitted to the masonry walls are modelled with beam elements [12], which have also been used to model the wooden trusses and rafters of the pavillion roof covering the tower. The mechanical properties of the tie rods and wooden elements are, respectively, $E=2.1 \cdot 10^{5}$ $\mathrm{MPa}, \nu=0.3, \rho=7850 \mathrm{~kg} / \mathrm{m}^{3}$ and $E=10000 \mathrm{MPa}, \nu=0.35, \rho=800 \mathrm{~kg} / \mathrm{m}^{3}$.

We assume the bell tower to be made of a homogeneous isotropic masonry-like material with Poisson's ratio $\nu=0.2$, Young's modulus $E$ and mass density $\rho$. Model updating is conducted by varying the parameters $E$ and $\rho$ in the following intervals

$$
\begin{aligned}
& 2.5 \cdot 10^{9} \mathrm{~Pa} \leq E \leq 5.5 \cdot 10^{9} \mathrm{~Pa}, \\
& 1700 \mathrm{~kg} / \mathrm{m}^{3} \leq \rho \leq 2100 \mathrm{~kg} / \mathrm{m}^{3},
\end{aligned}
$$

and calculating the first four natural frequencies of the tower for the linear elastic and nonlinear case, after having applied the structure's self-weight alone. The optimal values of $E$ and $\rho$, are determined by minimizing the functions 

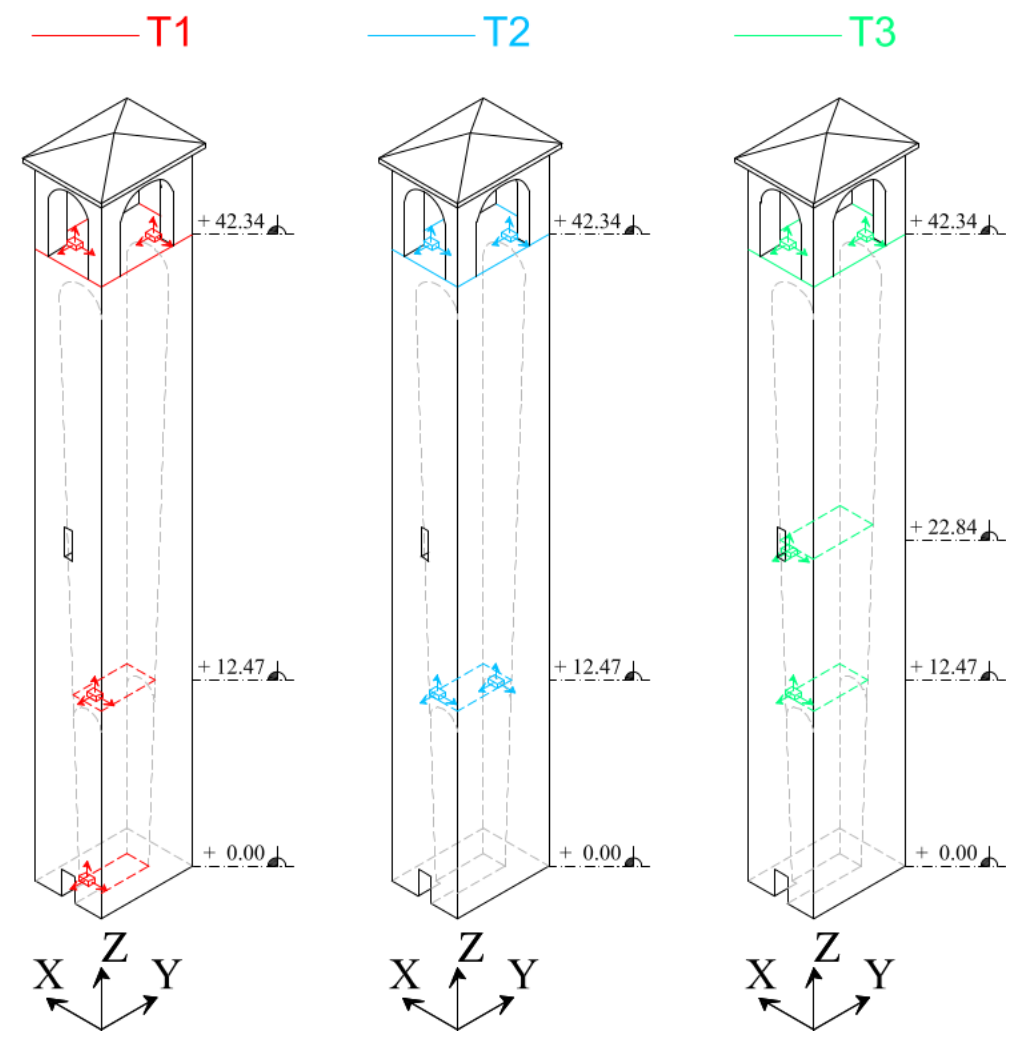

Figure 2: Sensors setup.

$$
\begin{gathered}
e^{l}(E, \rho)=\sum_{i=1}^{4}\left(f_{\mathrm{i}}^{l}(E, \rho)-f_{\mathrm{i}}^{\exp }\right)^{2}, \\
e(E, \rho)=\sum_{i=1}^{4}\left(f_{\mathrm{i}}(E, \rho)-f_{\mathrm{i}}^{\exp }\right)^{2},
\end{gathered}
$$

respectively for the linear and nonlinear cases, for $E$ and $\rho$ satisfying (4).

Figures 3 and 4 respectively show the functions $e^{l}$ and $e$ vs. $E$ and $\rho$. They reach their minimum values at $E=3.0 \cdot 10^{9} \mathrm{~Pa}$ and $\rho=2100 \mathrm{~kg} / \mathrm{m}^{3}$ for the linear elastic case and at $E=4.5 \cdot 10^{9} \mathrm{~Pa}$ and $\rho=2100 \mathrm{~kg} / \mathrm{m}^{3}$ for the nonlinear case. Figure 5 plots the two functions vs. $E$ for $\rho=2100 \mathrm{~kg} / \mathrm{m}^{3}$. The first four natural frequencies of the tower are shown in Table 1 , where the experimental values $f_{\mathrm{i}}^{\text {exp }}$ are shown for comparison with the numerical ones, in the linear elastic $\left(f_{\mathrm{i}}^{l}\right)$ and nonlinear $\left(f_{\mathrm{i}}\right)$ case. Columns $\Delta f_{\mathrm{i}}^{l}$ and $\Delta f_{\mathrm{i}}$ show the relative errors (absolute value) between the numerical and experimental values for the linear and nonlinear case, respectively. In the linear case the numerical frequencies differ from the experimental values by no more than seven percent; the nonlinear case is more accurate and with differences of less than three percent. Figure 6 shows the maximum principal fracture strains for the tower in equilibrium with its own weight. The crack distribution and the low fracture strain values indicate a modest level of cracking within the structure: the fracture strains are concentrated around the windows and lintels, as well as in the masonry supporting the vault under the bell chamber. This 


\begin{tabular}{cccccc}
\hline & $f_{\mathrm{i}}^{\text {exp }}$ & $f_{\mathrm{i}}^{l}$ & $\Delta f_{\mathrm{i}}^{l}$ & $f_{\mathrm{i}}$ & $\Delta f_{\mathrm{i}}$ \\
\hline Mode Shape 1 & 1.05 & 0.98 & 0.07 & 1.08 & 0.03 \\
\hline Mode Shape 2 & 1.30 & 1.24 & 0.05 & 1.28 & 0.02 \\
\hline Mode Shape 3 & 4.20 & 4.32 & 0.03 & 4.24 & 0.01 \\
\hline Mode Shape 4 & 4.50 & 4.38 & 0.03 & 4.52 & 0.004 \\
\hline
\end{tabular}

Table 1: Natural frequencies [Hz] of the tower: experimental values $f_{\mathrm{i}}^{\text {exp }}$, numerical values $f_{\mathrm{i}}^{l}$ of the linear elastic model; numerical values $f_{\mathrm{i}}$ of the masonry-like model.

\begin{tabular}{ccccc}
\hline & $\phi_{1}$ & $\phi_{2}$ & $\phi_{3}$ & $\phi_{4}$ \\
\hline$\phi_{1}^{l}$ & 0.998 & 0.039 & 0.019 & 0.020 \\
\hline$\phi_{2}^{l}$ & 0.038 & 0.997 & 0.008 & 0.011 \\
\hline$\phi_{3}^{l}$ & 0.003 & 0.008 & 0.810 & 0.580 \\
\hline$\phi_{4}^{l}$ & 0.024 & 0.000 & 0.580 & 0.800 \\
\hline \multicolumn{5}{c}{ Table $2:$ MAC- $M\left(\phi_{\mathrm{i}}^{l}, \phi_{\mathrm{j}}\right)$, for $\mathrm{i}, \mathrm{j}=1, \ldots, 4}$.
\end{tabular}

confirms the observations made upon visual inspection. Fracture strains are concentrated in regions of the structure quite far from those of the highest curvatures for the first mode shapes, which in fact remain very similar to those calculated in the linear elastic case. However, due to the nonlinearity of the constitutive equation adopted, the model updating procedure yields higher values of Young's modulus. Figures 7 and 8 show the first four mode shapes, calculated in the nonlinear case for the optimal values $\left(E=4.5 \cdot 10^{9} \mathrm{~Pa}, \rho=2100 \mathrm{~kg} / \mathrm{m}^{3}\right)$. As can be seen in Table 2, they are substantially equal to the linear elastic modes $\phi_{\mathrm{i}}^{l}$. The Figures clearly show that the first two mode shapes are flexural (along $X$ and $Y$ respectively), the third is torsional and the fourth is mixed (torsional and bending along $X$ ). The first four experimental mode shapes are depicted in Figures 9 and 10.

\section{CONCLUSIONS}

This paper describes a new numerical procedure, implemented in the finite element code NOSA-ITACA, for the modal analysis of masonry structures. Once the initial loads and boundary conditions have been applied to the finite-element model, the resulting non-linear equilibrium problem is solved. Then, a modal analysis is performed, by using the tangent stiffness matrix calculated by the code in the last iteration before convergence is reached. The incremental approach used by NOSA-ITACA allows the user to perform the modal analysis at the initial step, before application of any load to the structure, and then for different loading steps. The proposed procedure allows the user to automatically take into account the influence of the stress distribution on the system's stiffness matrix, thereby evaluating the effects of the presence of cracked material on the structure's dynamic properties. The method proposed has been applied to the "Clock Tower" in Lucca. The tower has been instrumented with seismometric stations and its first four natural frequencies determined via OMA techniques. Then, the NOSA-ITACA code has been employed, together with model updating techniques, in order to fit the experimental results. The model updating in the linear elastic case is compared to that in the nonlinear case, applied to the tower subjected to its own weight while taking into account the crack distribution induced by the load. 


\section{Acknowledgements}

This research has been supported by the Region of Tuscany (Project "MOSCARDO - ICT technologies for structural monitoring of age-old constructions based on wireless sensor networks and drones", 2016-2018) and the Cassa di Risparmio di Lucca Foundation (Project "TITANIO - Monitoring of historic masonry buildings via innovative sensors", 2016-2018). These supports are gratefully acknowledged.

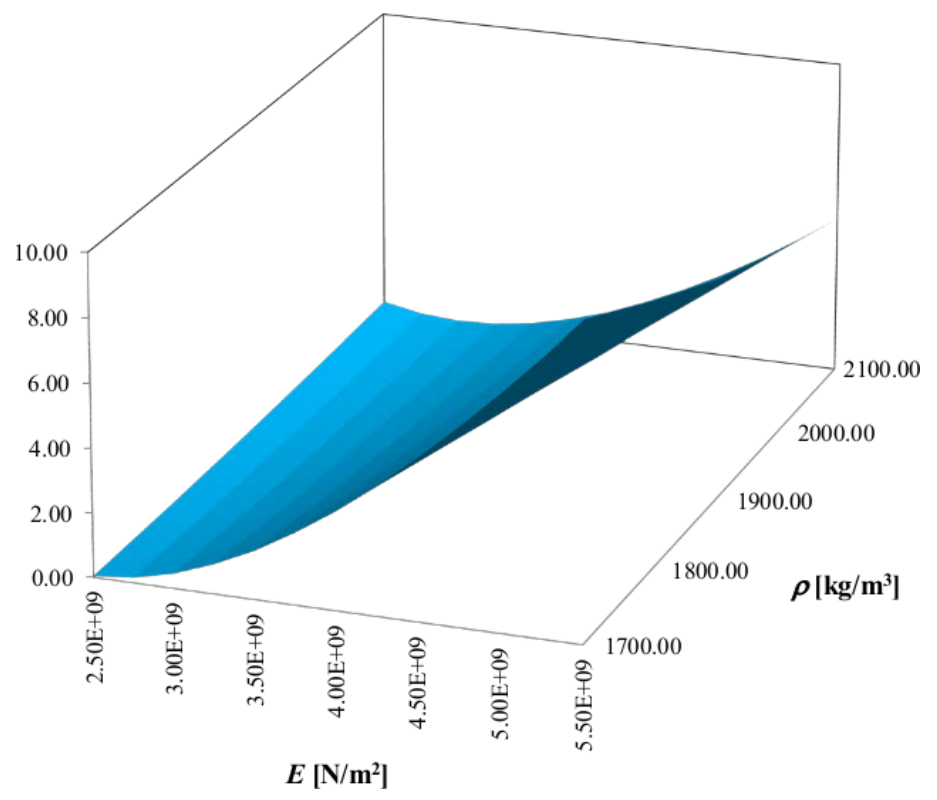

Figure 3: Function $e^{l}(E, \rho)$ : linear case.

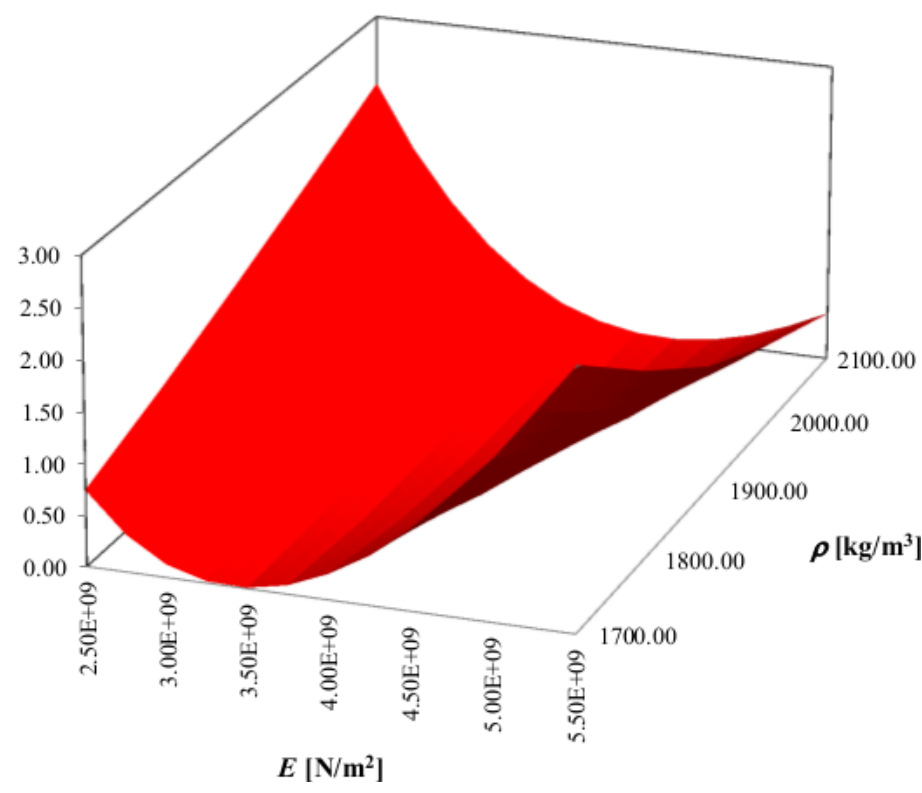

Figure 4: Function $e(E, \rho)$ : nonlinear case. 


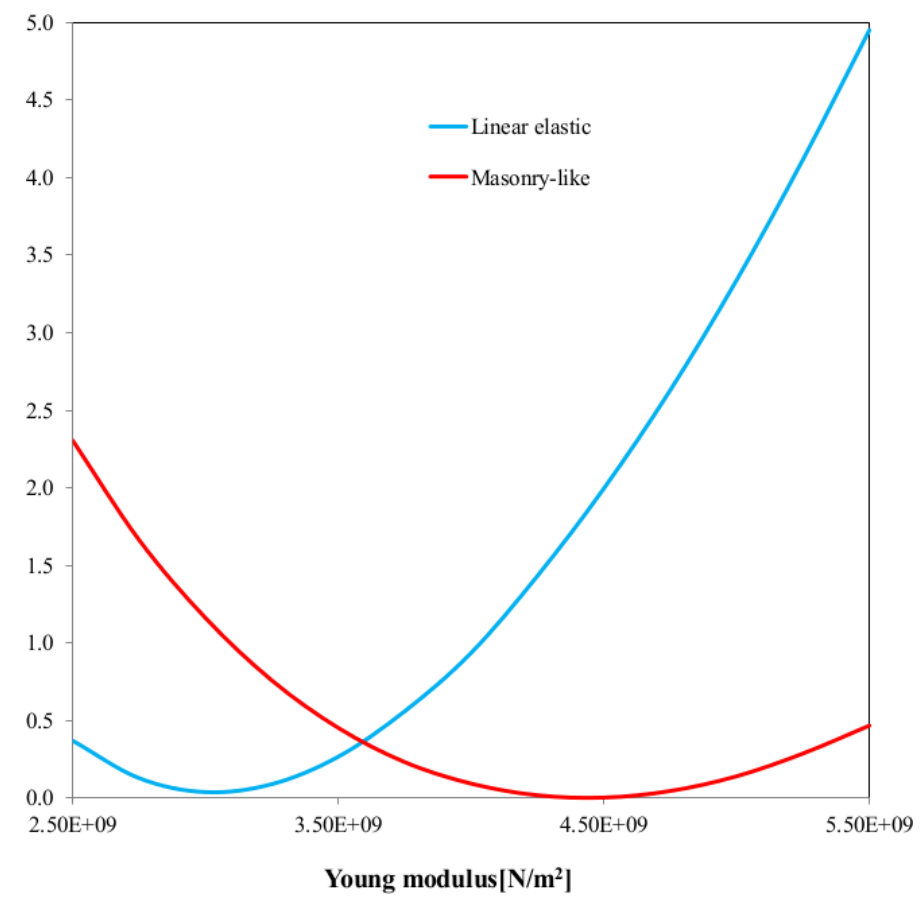

Figure 5: Functions $e(E, \rho)$ (red line) and $e^{l}(E, \rho)$ (blue line) vs. $E$ for $\rho=2100 \mathrm{~kg} / \mathrm{m}^{3}$.
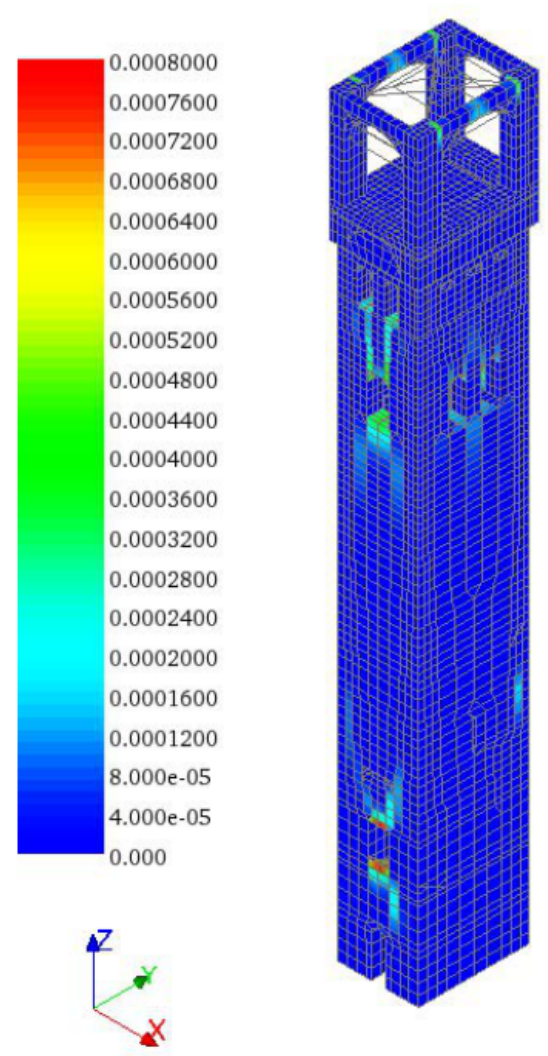

Figure 6: Maximum principal fracture strains. 

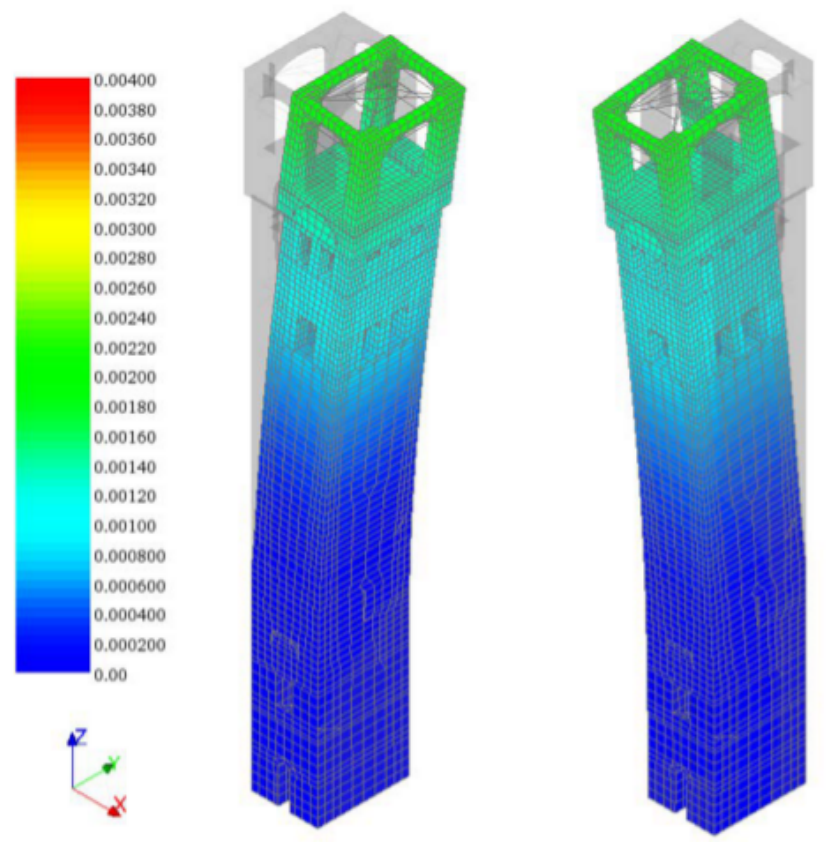

Figure 7: Mode shapes $\phi_{i}, i=1,2$ of the "Clock Tower" in the nonlinear case, for $E=4.5 \cdot 10^{9} \mathrm{~Pa}, \rho=$ $2100 \mathrm{~kg} / \mathrm{m}^{3}$.
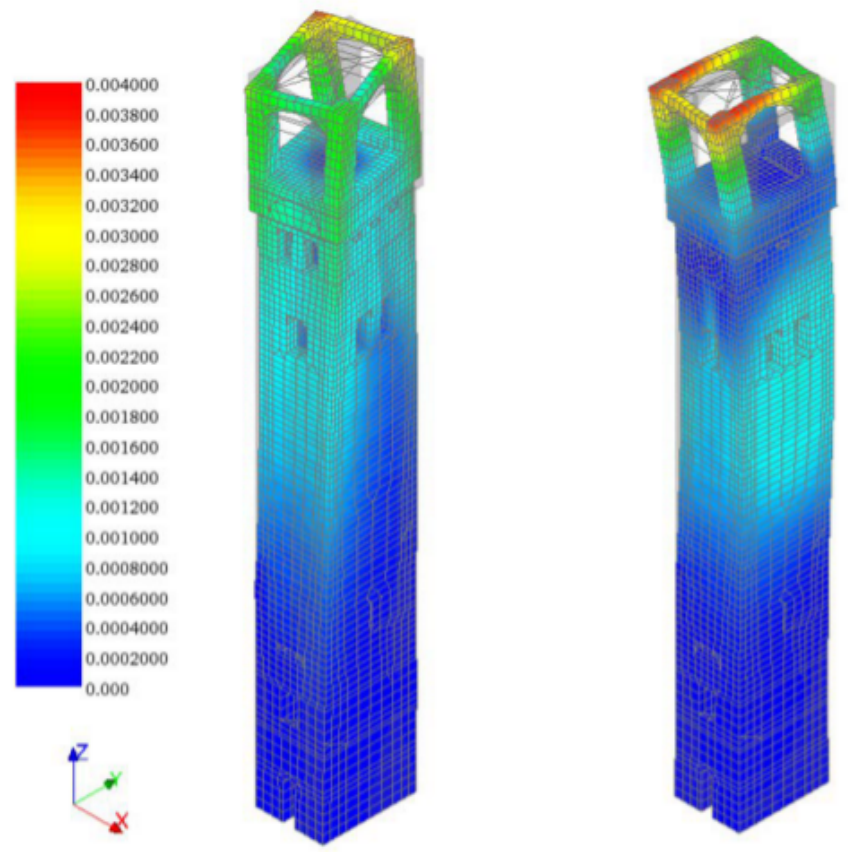

Figure 8: Mode shapes $\phi_{i}, i=3,4$ of the "Clock Tower" in the nonlinear case, for $E=4.5 \cdot 10^{9} \mathrm{~Pa}, \rho=$ $2100 \mathrm{~kg} / \mathrm{m}^{3}$. 

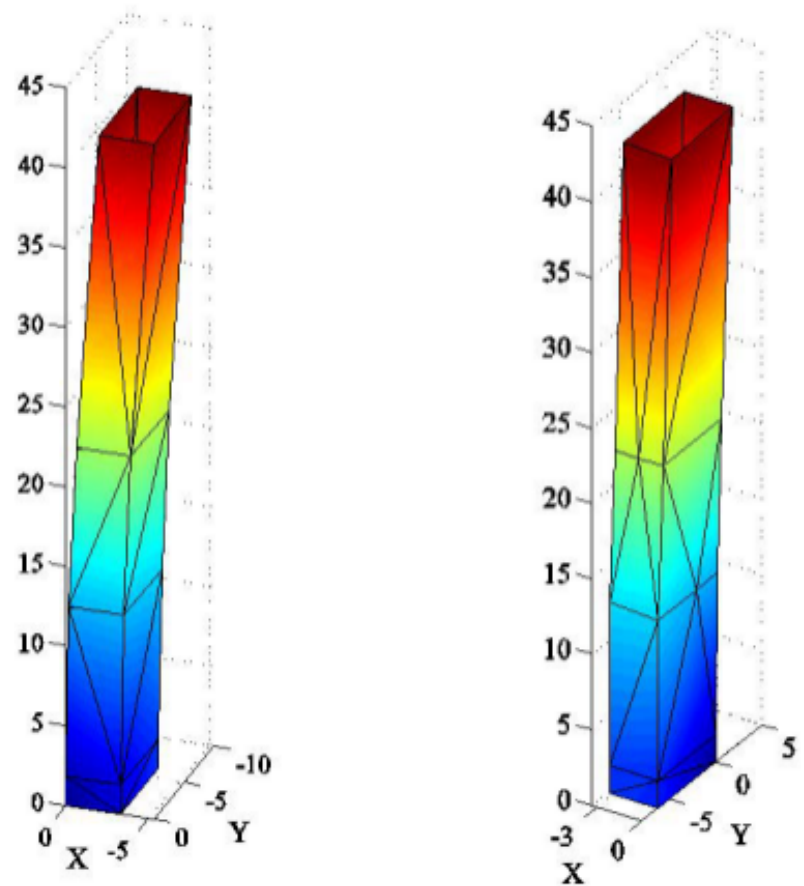

Figure 9: First and second experimental mode shapes of the "Clock Tower".
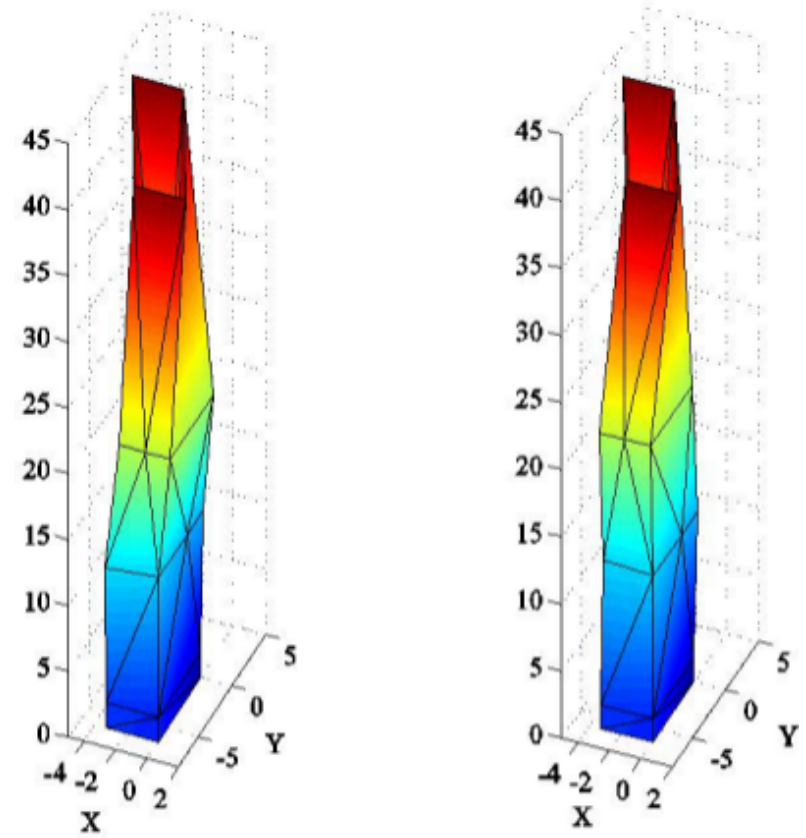

Figure 10: Third and fourth experimental mode shapes of the "Clock Tower".

\section{REFERENCES}

[1] W. Ren, G. De Roeck, Structural Damage Identification using Modal Data. I: Simulation Verification. Journal of Structural Engineering, 128(1), 87-95, 2002.

[2] W. Ren, G. De Roeck, Structural Damage Identification using Modal Data. II: Test Verifi- 
cation. Journal of Structural Engineering, 128(1), 96-104, 2002.

[3] M. Jayanthan, V. Srinivas, Structural Damage Identification Based on Finite Element Model Updating. Journal of Mechanical Engineering and Automation, 5(3B), 59-63, 2015.

[4] P. Pineda, Collapse and upgrading mechanisms associated to the structural materials of a deteriorated masonry tower. Nonlinear assessment under different damage and loading levels. Engineering Failure Analysis, 63, 72-93, 2016.

[5] L.F. Ramos, G. De Roeck, P.B. Loureno, A. Campos-Costa, Damage identification on arched masonry structures using ambient and random impact vibrations. Engineering Structures, 32, 146-162, 2010.

[6] T.T. Bui, A. Limam, Q.B. Bui, Characterisation of vibration and damage in masonry structures: experimental and numerical analysis. European Journal of Environmental and Civil Engineering, 18(10), 1118-1129. 2014.

[7] E. Cakti, O. Saygili, J.V. Lemos, C.S. Oliveira, A parametric study of the earthquake behaviour of masonry minarets. Proceedings of the Tenth U.S. National Conference on Earthquake Engineering Frontiers of Earthquake Engineering, 10NCEE, Anchorage, Alaska, July 21-25, 2014.

[8] M. Girardi, M. Lucchesi, Free flexural vibrations of masonry beam-columns. Journal of Mechanics of Materials and Structures, 5(1), 143-159, 2010.

[9] G. Del Piero, Constitutive equations and compatibility of external loads for linear elastic masonry-like materials. Meccanica, 24, 150-162, 1989.

[10] S. Di Pasquale, New trends in the analysis of masonry structures. Meccanica, 27, 173-184, 1992.

[11] M. Lucchesi, C. Padovani, G. Pasquinelli, N. Zani, Masonry constructions: mechanical models and numerical applications. Lecture Notes in Applied and Computational Mechanics, Springer-Verlag. 2008.

[12] V. Binante, M. Girardi, C. Padovani, G. Pasquinelli, D. Pellegrini, M. Porcelli, NOSAITACA 1.0 documentation. http://www.nosaitaca.it/software/, 2014.

[13] M. Girardi, C. Padovani, D. Pellegrini, Modal analysis of masonry structures. arXiv:1611.00531v1 [cs.CE], 2 November 2016.

[14] R. Brincker, C. Ventura, Introduction to Operational Modal Analysis. John Wiley \& Sons, 2015.

[15] R.M. Azzara, M. Girardi, C. Padovani, D. Pellegrini, The Medieval Clock Tower in Lucca: dynamic monitoring and numerical analysis. Internal Report ISTI, 2017.

[16] M. Porcelli, V. Binante, M. Girardi, C. Padovani, G. Pasquinelli, A solution procedure for constrained eigenvalue problems and its application within the structural finite-element code NOSA-ITACA. Calcolo, 52(2), 167-186, 2015. 